\title{
INFLUENCE OF EXTRACTION METHODS ON THE HEPATOTOXICITY OF AZADIRACHTA INDICA BARK EXTRACT ON ALBINO RATS
}

\author{
N. NWACHUKWU AND E. J. IWEALA
}

(Received 4, March 2008; Revision Accepted 2, February 2009)

\section{ABSTRACT}

The influence of extraction methods: Cold aqueous (CA) hot aqueous (HA) and alcoholic extraction (AE) methods on the hepatotoxic effect of Azadirachta indica bark extract $(A B C)$ was investigated using albino rats. A total of forty eight rats were divided into three groups of sixteen rats equally for the extraction methods. Each group was subdivided into four rats to represent control, low, medium and high doses of the extract. The control group received no extract while the other groups were administered the various concentrations (doses) intraperitoneally twice daily for seven (7) days before they were all sacrificed under light chloroform and used for the analysis. Parameters determined include glucose, cholesterol and triglycerol. Also alkaline phosphatase (ALP), Aspartate amino transferase (AST) and alanine amino transferase (ALP) activities were determined. The result shows that glucose levels decreased from $85.75+2.85$ to $65.00+12.05$ in high concentration of C.A. Similar decreases were obtained from HA and $\mathrm{AE}$ extraction methods. Cholesterol levels also decreased from $111,63+1.02$ to $53.75+0.90$ in the high concentration $\mathrm{CA}$, and similarly decreased in $\mathrm{HA}$ and $\mathrm{AE}$ extraction methods. Also triglycerol levels decreased from $66.49+0.95$ to $21.02 \pm 0.30$ in the high concentration of $\mathrm{CA}$, and also decreased respectively in both $\mathrm{HA}$ and $\mathrm{AE}$ extraction methods. Similarly, the activities of the enzymes decreased in all the extraction methods, and for the different concentrations over the control except for the activities of ALP which increased generally in CA method. This implies that $A B E$ using $\mathrm{HA}$ and $\mathrm{AE}$ methods in non hepatotoxic while there is possibility of hepatotoxicity of the obstructive type if CA extraction method is used.

KEY WORDS: Medicinal plants; Hepatotoxicity; Liver enzymes; Serum lipid, and serum glucose.

\section{INTRODUCTION}

Azadirachta indica (A juss) commonly referred to as "dogonyaro" or Neem belongs to the specie of the family meliaceae. A. indica is perhaps the most studied and used medicinal plants of all ages. It also has the unique property of adapting to wide range of climatic conditions from semi arid to semi humid, and can even thrive well in places with less than $500 \mathrm{~mm}$ of rain for a year (Prakash and Roa, 1997).

Various parts of the Neem tree (leaves, bark, roots oil, fruits, kernel, flowers, etc) have been used therapeutically in folk medicine,(Thornborogh, 1997). Equally various plants extracts have been used for the treatment of such diseases like leprosy, intestinal worm, skin ulcers, cough, asthma, diabetes, inflammatory diseases, etc (Akah et al. 1992, Chetterjee and Pankrashi 1994, Biswas et al 2002, Badam et al, 1987). The bark of Neem tree is known to possess tannins used in tannery and dyeing, phenoilc compounds (Saliic acid. gallocatechin) considered to be the active principles involved in the anti inflammatory activity (Lewis, 2001). Toxicological studies using $2 \mathrm{~g} / \mathrm{kg}$ body weight, showed no lethal effect, with no apparent change in relative organ weight, hematological parameters, enzyme levels and histopathology of several organs. In acute and subacute toxicity studies using bark extract of $1 \mathrm{~g} / \mathrm{kg}$ and $0.6 \mathrm{~g} / \mathrm{kg}$ body weight for fourteen days, there was no lethal effect. However, leaf extract given to goats at $200 \mathrm{mg} / \mathrm{kg}$ for eight weeks showed decrease in body weight, weakness, anorexia and histopathological defects. There was also hemorrhage, congestion and degeneration in the liver, kidney, lung, brain and seminiferous tubules (Niranjan et al, 1993).

Nwachukwu and Igwenyi, (2006) has reported that hepatotoxic effect of root extract is dose dependent and strongly influenced by extraction method. They concluded that only ethanolic extraction has possible hepatotoxic effect whereas cold and hot aqueous extractions have no injurious effect. These extraction methods are mostly common among the natives that use this plant as anti malarial remedy. Opinion on the possible hepatotoxic effect of Neem extract is varied. Some even suggested possible hepatotoxic protective effect (Akah, et al, 1992). It is therefore important to investigate these common methods, and the various plant parts to know the extent or not of any possible hepatotoxic effect.

In this study, the influence of extraction methods on the hepatotoxicity of $A$. indica bark extract was investigated using albino rats.

\section{MATERIALS AND METHODS}

Fresh and uninfected bark of A-indica was collected from the Neem tree growing at the Botanical Garden of the University of Nigeria, Nsukka.

N. Nwachukwu, Department of Biochemistry, School of Science, Federal University of Technology, P.M.B.1526 Owerri.

E. J. Iweala, Department of Biochemistry, Faculty of Biological and Physical Science, Abia State University, Uturu. Abia State. 


\section{Sample preparation:}

The bark was cleaned and dried in a desiccator to constant weight before grinding in a milling machine to powdered form. This was sieved through a micro sieve of $1 \mathrm{~mm}$. The fine powder form was divided into three equal parts. One part was soaked in cold water overnight to serve as cold extract (CA) another part was boiled in $150 \mathrm{ml}$ of distilled water for $1 \mathrm{hr}$ and allowed to cool before filtering (HA). The last part was extracted using soxhlet extractor, and ethanol as solvent according to the method of Njoku et al, (1996).

This serves as the alcoholic extract (AE).

Determination of concentration: The filtrate, $10.0 \mathrm{ml}$ was heated to dryness using a desiccator and the concentration for the filtrate calculated by subtracting the weight of the desiccator from the weight of the desiccator and the residue after dryness.

Animals and Treatment: A total of forty eight rats, mean body weight $120.00 \pm 3.15 \mathrm{~g}$ were purchased from the Animal house of the Dept. of Veterinary medicine, U.N.N. They were divided into three groups of sixteen rats for old aqueous (CA), hot aqueous (HA), and alcoholic extraction (AC) methods. Each group was further separated into four rats and housed in metallic cages to represent, control, low, [(50mg/kg or $4.75 \mathrm{ml})$, medium $(100 \mathrm{mg} / \mathrm{kg}$ or $9.15 \mathrm{ml}$, and high $(150 \mathrm{mg} / \mathrm{kg}$ or $14.10 \mathrm{ml}$ ) concentrations of the extract in each method. The control received only water and the normal rat rations ad libitum. Administration of extract was by intraperitoneal twice daily for seven days].

Preparation of serum: Eighteen hours after the last administration, all the rats were sacrificed using light chloroform anesthesia. Using a sterilized $2.0 \mathrm{ml}$ syringes and needles, blood was collected by cardiac puncture, and allowed to stand for $30 \mathrm{~min}$ retracting time. This was centrifuged at $8000 \mathrm{xg}$ for $10 \mathrm{~min}$, and the serum collected and used for all the analysis.

Determination of Glucose, Cholesterol and Triglycerol Serum contents: Glucose oxidase method according to Trindax (1969) was used to determine glucose, while triglycerol was determined by the method of Fossati and Prencipe, (1982). Cholesterol was determined by the method of Pearson et al, (1953).

Enzyme Assay: The activities of the enzymes were assayed from the serum. Alkaline phosphatase (ALP) activity was determined by the method of Kochmar and Moss, (1986) while aspartate amino transferase (AST) and alanine amino transferase (ALT) activities were determined by the method of Reitman and Frankel, (1957).

Statistical Analysis: The degree of significance between the various concentrations and the control was analyzed using ANOVA where $p \geq 0.05$ was regarded as significant.

\section{RESULT}

In tables 3.1, 3.2 and 3.3, the result shows that glucose levels in $\mathrm{CA}, \mathrm{HA}$, and $\mathrm{AE}$ extractions decreased in a dose dependent manner over the control from $85.75 \pm$ to $65.00 \pm 12.08 ; 47.10 \pm 0.62$ to $19.78 \pm 7.66$; and $94.70 \pm 9.70$ to $62.35 \pm 5.56$ respectively. Similar results were obtained for cholesterol and triglycerol. In tables 3.4, 3.5 and 3.5, the activities of the enzymes decreased in all the methods. The activities of AST, in CA, HA and $\mathrm{AE}$ extraction methods, decreased from the control to the highest concentration $18.18 \pm 0.40$ to $14.42 \pm 1.08$; $15.23 \pm 3.19$ to $14.50 \pm 1.50$; and $19.25 \pm 4.42$ to $17.50 \pm 4.30$ respectively. Similar results were obtained for $A \bar{L}$ ? and $A L T$, except for the activities of ALP in CA which rather increased.

\section{DISCUSSION}

There was a general decrease in the level of glucose in all the methods studied as compared to the control (table 3.1). The variance was found to be significant at $p \leq 0.05$. The decrease could be attributed to the ability of Neem extract to fully mobilize glucose in animal models and therefore enhance utilization. It is possible that a flavonoid, nimbidin and quarcetin found in A. indica could cause hemodilaiton effect, thereby leading to effective glucose mobilization. This hypoglycemic effect is important in the use of $A$. indica extract in the treatment of diabetes disease.

Cholesterol and triglycerol levels generally decreased in all the methods (table 3.2 and 3.3) as compared to the control. The decreases were also found to be statistically significant $(p \leq 0.05)$. The bark extract may have stimulated increased transport of cholesterol by HDL to the liver for conversion into bile acid or probably depressed the activities of such hormones like thyroxine and estrogen leading to decreased in the level of cholesterol (Neem and Cox, 2000). The hypocholesterolemic effect of Neem extract makes it effective as an anticarcinogenic agent and also reduces the risk of artherosclerosis (Chiamasamy et al, 1993). Infact, protective effect against oxidative stress could be by reduction in the formation of lipids. Again this may be due to the antioxidant properties of such flavonoids like quercetin found in A. indica extract. Akah et al (1992), suggested that a low concentration of $A$. indica extract has hapatoprotective ability. This is demonstrated by the reduction in the activities of the AST, and ALT, and ALP in $\mathrm{HA}$ and $\mathrm{AE}$.

The result also shows that apart from ALP, the activities of other enzymes (AST and ALT) decreased in all the methods used (table $3.4,3.5$ and 3.6) as compared to the control. These decreases were also significant statistically $(p \leq 0.05)$ and represents possibly inhibitory effect on the activities of these enzymes. ALP activities increased, generally in CA method. The increase was dose dependent though not as high as to suggest any liver injury. According to Mclntyre and Rosalki, (1991), ALP is employed in the diagnosis of two groups of conditions, hapatobiliary and bone diseases. In intrahepatic obstruction of the bile flow e.g. invading cancer, action of drugs or jaundice, ALP activity is raised to a lesser extent (2-5times the upper limit). An elevated ALP level can also be due to rapid bone growth, renal or intestinal damage (Grove et al, 1998). The result of this study therefore suggests that there could be hepatotoxicity of the biliary cirrhosis type at 
elevated concentration of cold aqueous bark extract of A. indica.

\section{CONCLUSION}

In conclusion, the study has shown the hypoglycemic and hypocholesterolemic effects of the bark extract of $A$. indica in all the methods used. Both $H A$ and $A E$ methods are relatively safe whereas in $C A$, there could be liver injury at elevated concentration of the bark extract (BEA).

TABLE 3.1 SERUM GLUCOSE CONTENT (mg/ml)

\begin{tabular}{|l|l|l|l|}
\hline DOSAGE & METHODS & \multicolumn{3}{l|}{} \\
\hline & CA & HA & AE \\
\hline CONTROL & $85.75 \pm 2.85$ & $47.10 \pm 0.62$ & $94.70 \pm 9.70$ \\
\hline LOW $50 \mathrm{mg} / \mathbf{k g}$ & $78.35 \pm 15.46$ & $46.24 \pm 6.35$ & $74.41 \pm 23.39$ \\
\hline MEDIUM $\mathbf{~ g / k g}$ & $71.43 \pm 29.81$ & $31.24 \pm+3.90$ & $79.11 \pm 49.20$ \\
\hline HIGH $150 \mathrm{mg} / \mathbf{k g}$ & $65.00 \pm 12.08$ & $19.78 \pm 7.66$ & $62.35 \pm 5.56$ \\
\hline
\end{tabular}

TABLES 3.2 SERUM CHOLESTEROL CONTENT (mg/ml)

\begin{tabular}{|l|l|l|l|}
\hline DOSAGE & METHODS & \multicolumn{3}{l|}{} \\
\hline & CA & HA & AE \\
\hline CONTROL & $111.63 \pm 1.02$ & $68.87 \pm 1.70$ & $29.34 \pm 7.40$ \\
\hline LOW 50 & $67.38 \pm 0.54$ & $67.75 \pm 3.26$ & $22.28 \pm+6.38$ \\
\hline MEDIUM & $62.55 \underline{+0.43}$ & $59.25+4.14$ & $21.74 \pm 6.38$ \\
\hline HIGH & $53.75 \pm 0.90$ & $52.57 \pm 3.03$ & $18.80 \pm 2.92$ \\
\hline
\end{tabular}

TABLE 3.3 SERUM TRIGLYCEROL CONTENT (mg/ml)

\begin{tabular}{|l|l|l|l|}
\hline DOSAGE & METHODS & HE \\
\hline & CA & HA & $136.32 \pm 19.60$ \\
\hline CONTROL & $66.49 \pm 1.95$ & $65.13 \pm 1.17$ & $115.53 \pm 14.70$ \\
\hline LOW & $40.32 \pm 1.05$ & $59.10 \pm 4.49$ & $117.90 \pm 12.50$ \\
\hline MEDIUM & $28.52 \pm 0.36$ & $58.69+4.31$ & $115.53 \pm 14.70$ \\
\hline HIGH & $21.02 \pm 0.03$ & $53.97 \pm 4.83$ & \\
\hline
\end{tabular}

$\mathrm{CA}=$ cold aqueous extraction

$\mathrm{HA}=$ hot aqueous extraction

$\mathrm{AE}=$ alcoholic extraction

All values are \pm SD 3 determination

ENZYME ASSAY

TABLE 3.4 SERUM ACTIVITY (I.U/L)

\begin{tabular}{|l|l|l|l|}
\hline DOSAGE & METHODS & \multicolumn{3}{l|}{} \\
\hline & CA & HA & AE \\
\hline CONTROL & $18.18 \pm 0.47$ & $66.58 \pm 0.38$ & $43.20 \pm 25.00$ \\
\hline LOW & $57.41 \pm 0.57$ & $61.19 \pm 4.87$ & 43.3715 .80 \\
\hline MEDIUM & $77.78 \pm 0.18$ & $57.47 \pm 24.30$ & $46.89 \pm 5.44$ \\
\hline HIGH & $79.08+0.26$ & $76.34 \pm 4.12$ & $42.66 \pm 43.00$ \\
\hline
\end{tabular}

TABLE 3.5 SERUM ACTIVITY (I.U/L)

\begin{tabular}{|l|l|l|l|}
\hline DOSAGE & METHODS & HA \\
\hline & CA & $15.23 \pm 3.19$ & $19.25 \pm 4.92$ \\
\hline CONTROL & $18.18 \pm 0.40$ & $15.50 \pm 1.50$ & $23.50 \pm 3.75$ \\
\hline LOW & $6.48 \pm 0.61$ & $14.50 \pm 2.50$ & $23.89 \pm 35.33$ \\
\hline MEDIUM & $7.41 \pm 1.08$ & $14.50 \pm 1.50$ & $17.50 \pm 4.33$ \\
\hline HIGH & $14.42 \pm 1.08$ & & \\
\hline
\end{tabular}


TABLE 3.6 SERUM ACTIVITY (I.U/L)

\begin{tabular}{|l|l|l|l|}
\hline DOSAGE & METHODS & HA & AE \\
\hline & CA & $29.25 \pm 3.19$ & $29.75 \pm 19.70$ \\
\hline CONTROL & $32.09+3.09$ & $25.00 \pm 4.89$ & $24.50 \pm 14.90$ \\
\hline LOW & $29.69 \pm 5.83$ & $25.50 \pm 2.50$ & $23.00 \pm 6.00$ \\
\hline MEDIUM & $31.10 \pm 2.23$ & $22.00 \pm 1.73$ & $27.50 \pm 45.00$ \\
\hline HIGH & $29.56 \pm 3.92$ &
\end{tabular}

CA = Cold aqueous extraction

$\mathrm{HA}=$ Hot aqueous extraction

AE = Alcoholic extraction

All values are + SD 3 determination.

\section{REFERENCES}

Akah, P.A., Offiah. V. N. and Onuagu E., 1992. Hepatotoxic Effect of A. Indica leaf Extract in Rabbits. Protoz. 63, 311-319.

Badam, L., Deolanker R. P., Kulkami, M., Wagsampgi, M. and Wagh U. V., 1987. In Vitro Antimalaria Activity of Neem Leaf and Seed Extracts. Indian J. Malariology 24, 111-117.

Biswas, K. I., Ranjit, R. B., Uday, B. and Ishita, C., 2002. Biological Activities and Medicinal Properties of Neem. (A. Indica) Current Science. 82 (11): 1336-1345.

Charterjee, A. and Pakrashi, S., 1994. Treatise on Indian Medicinal Plants: IBH Publ. New Delhi.

Chinmasamy, N., Harishankar, N., Kuma, P.U. and

Rukmin, C., 1993. Toxicological Studies on Debitterized Neem Oil. Food chem... Toxicol. 32 (4): 21-26.

Fossati, P. and Prencipe, E., 1998. Triglycerol. Clin. Chem. 28, 2007-2080.

Grove, D. LO., Blair, A. J. and Bundy, D. A., 1998. Alkaline Phosphatase Activity: Am J. Trop. Medi. 130, 344-349.

Katsuri, M., Manvivannan, B., Ahmed, R., Sheikh, P. O. and Pathan, K. M., 1995. Human Toxicology Changes in Epididym al Structures and Functions of Albino Rates Treated with A. Indica Leaves. Ind. J. Expt. Boil. 33,725-729.

Kochmar, J. F. and Moss, D.N., 1986. Enzymes. In: Textbook of Clinical Chemistry (Tietz. N. W. Ed). N.B Saunder and Comp U.S.A.

Lewis, K. C., 2001. Uses of Medicinal Plants, Am. J. Trop. Med. 140; 261-263.
Melntyre, N. and Rosaiki, S., 1991. Biochemical Investigations in the Management of Liver Diseases In: Testbook of Hepatology (Mclntyre N. Ed). Oxford univ. Press.

Nelson, D. L. and Cox , M. M., 2000. Principles of Biochemistry $\left(3^{\text {rd }}\right.$ Ed) Worth Publ. New York.

Niranjan, R., Shananan, K., Madynathar, K. M. and Ramji, N., 1993. Azadiractin II from A. indica. Phytochem. (2): 561-562.

Njoku, O. U., Ononogbu, I. C., Nwanguma B. C. and Okide, B. G., 1996. Investigation on Monodora Myristica Seed Oil. J. Herbs, Spices and Med. Plants. 4(2): 57-62.

Nwachukwu, N. and Igwenyi, I., 2006. Influence of Extraction Methods on the Hepatotoxicity of A. Indica Root. Journal of Res, in Biosci. 2(4), 1013.

Pearson, J., Stem, S. S. and NoGavack, T. H., 1953. Determination of Serum Cholesterol. Analy. Chem. 25, 813.

Praskash, A. and Rao, J., 1997. Botanical pesticides in Agriculture. Lewis Publ. New Delhi India.

Reitman, S.N. and Frankel, S., 1957. Determination of the Transaminases. Am. J. Clin Pathol. 28, 5663.

Stryer, L., 1995. Biochemistry; Freeman and Comp. U.S.A.

Thornborough, J., 1997, Neem. An Ancient Cure for Modern World. Neem Foundation. 1, 15-17.

Trindax, P., 1969. Determination of Serum Glucose Ann. Clin. Biochem. 6, 24-27. 